\title{
Effect of Wavy Fins on Thermal Performance of Double Pass Solar Air Heater
}

\author{
Jalal M. Jalil (1) *, Rasha F. Nothim, Mustafa M. Hameed \\ Department of Electromechanical Engineering, University of Technology, Baghdad, Iraq \\ *Corresponding author Email: 50003@uotechnology.edu.iq
}

\section{H I G H L I G H T S}

- New arrangements of the wavy fins structure were implemented on the absorber.

- The wavy fins obstruct the flow on both passes of the double passes collector.

- Thermal efficiency reached $84 \%$ with the new arrangements.

\section{A R T I C L E IN F O}

Handling editor: Muhsin J. Jweeg

Keywords:

Experimental and Numerical Investigation

Thermal Performance

Absorber Air Collector

Corrugated Fins

\section{Introduction}

Solar air heating is a technology of renewable energy in which the energy from the sun is captured by an absorbing medium and used for heating air. A typical solar air heater is a flat plate collector with an absorbent layer covered from the top side with glass cover and isolated from the bottom with thermal isolation [1]. A double pass flat plate collector is advanced design of the solar collector, the purpose of using the double pass method is to reduce the heat transfer with the ambient thus to increase the system thermal efficiency [2]. To increase the rate of heat transfer in solar air heater fins, obstacles, ribs and roughness materials on the absorber plate could extend the surface of solar air heaters area [3]. The insertion of fins in the direction of fluid flow is an important way to increase the overall heat transfer by increasing the surface of solar air heater, while raising the coefficients of convection heat transfer [4]. The efficiency of the solar air heater can be improved by improving the effect of free and forced convection and increasing the area of the heat transfer [5]. And by making turbulence flow of air inside the channels by corrugated surface [6]. Solar air heating technologies also face some disadvantages, Small heat transfer coefficient within the absorber plate and in the air flow is one of the main problems [7].

Many studies was carried out to calculate the performance of one pass, corrugated, solar air heaters with various dimensions channels of air and for various mass flow rates of air and study its effect on thermal efficiency investigated by Choudhary et al. [8] Double pass finned plate solar air heater and v-corrugated plate were experimentally and theoretically, results presented that v-corrugated plate double pass solar air heater is 9.3-11.9\% More productive versus double pass-finned plate solar air heater examined by El-Sebaii et al. [9] Another study for double pass solar air collector, the air flows on both sides of the absorber plate to reduce the heat losses and that will lead to efficiency enhancement was done by Alam and Kim.[10] Improving the solar air collector by attaching fins, packed beds, or roughness surface are commonly used in solar air heater experimentally examined by Duffie and Beckman [11]. The effect of dimensions of the flow passage on the efficiency, the temperature improving and the pressure drop were examined on five different arrangements of corrugated and plane solar air heaters was studied by Jouybari and Lundström [12]. Garg et al. have proven that an active way to improve heat transfer is by adding fins in the direction of air flow. Many fin geometries, such as wavy, perforated and multi-louvered fins, plane and offset strip are extending the surface area density of solar air heater, moreover to improve the convection heat transfer 
coefficient. Therefore Wavy fins for their simplicity are considered most promising for production and potential for improved thermo-hydraulic efficiency [13-14]. Many researchers have studied the various performances of plane fins and other geometries. Proposed a numerical model for corrugated fins Predicting the effect of device, operating and meteorological parameters on solar air heater thermal and thermohydraulic efficiency With the fine, they observed a $20.4 \%$ increase in thermal efficiency when they increase the pressure drop at mass flow rate of $0.026 \mathrm{~kg} / \mathrm{s}$ and fin spacing $2.5 \mathrm{~cm}$, observed by Priyam et al. [15] For another analysis it was investigated the impact of the collector aspect ratio on the thermal efficiency of solar air heater with wavy fin absorber also done by Priyam A et al.[16] Adding wavy fins in parallel with the fluid flow rises the quantity of heat transfer in the solar air heater, also studied the effect of fins spacing on the thermal efficiency examined by Abhishek Priyam et al. [17]

In this study experimental investigation will be done on solar air heater with wavy fins attached to the absorber in parallel to the air flow in different number of waves, in each fin 3 waves and 7 waves fin. The plane absorber also will be investigated for performance comparison with finned absorbers. The effect of mass flow rate, solar radiation intensity and the fins arrangement on the thermal efficiency will be studied.

\section{Experimental set-up equipment's}

The experimental equipment has been planned, made and experienced as shown in Figure 1. The simulators has been use 3 halogen lamps, the rated power for each one $1000 \mathrm{~W}$. Voltage regulator used to control the lamps voltage and thus to control the light intensity.

The collector consist from double pass, aluminum absorber in between and glass cover. The dimension of each pass 120 $\mathrm{cm}$ length, $35 \mathrm{~cm}$ width and $4 \mathrm{~cm}$ height and $5 \mathrm{~cm}$ gap between two passes. The air inters from the upper pass and flowing on the absorber then through the gap to the bottom pass to be sucked out by air blower as shown in Figure 2 . The absorber dimensions are $35 \mathrm{~cm}$ width, $120 \mathrm{~cm}$ length and $0.7 \mathrm{~mm}$ thickness. The glass cover thickness is $6 \mathrm{~mm}$ and collector is thermally isolated. The collector equipped with centrifugal air blower controlled by speed controller on the entrance to suck the air . The wavy fins attached to the absorber in both passes as shown in and Figure 3. In this Study, two type of finned absorber, with two different fins geometries arrangement have been used, first type 3 waves, the second type is 7 waves, all made from aluminum as shown in Figure 4 with thermal conductivity $205 \mathrm{~W} / \mathrm{m}$. K. The fins attached in parallel to the absorber in both upper and lower sides, as shown in Fig.4. The mass flow rate changing rate from $0.0085 \mathrm{~kg} / \mathrm{s}$ to $0.0214 \mathrm{~kg} / \mathrm{s}$, and the solar radiation from $400 \mathrm{~W} / \mathrm{m}^{2}$ to $800 \mathrm{~W} / \mathrm{m}^{2}$, the solar radiation measurement have been taken for 10 points along the collector and the average of these readings is considered. The result obtained have been compared to the plane absorber results. The devices have been used for measuring are 8 numbers of temperature Recorder 2 Channels (Model: LNI-T UT320D), air speed measuring device (Anemometer Model: LNT-I UT363) and Solar power meter (Model: CEM DT-1307).

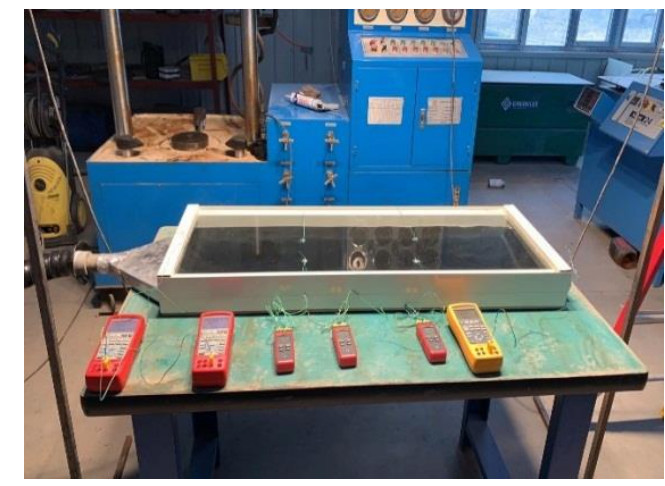

(A)

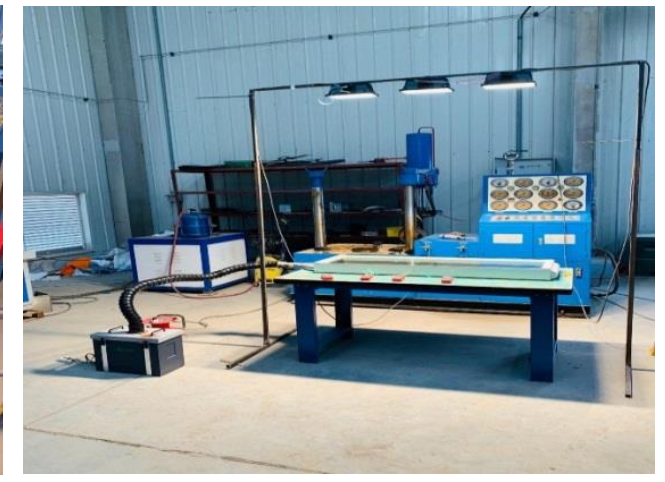

(B)

Figure 1: Experimental Setup

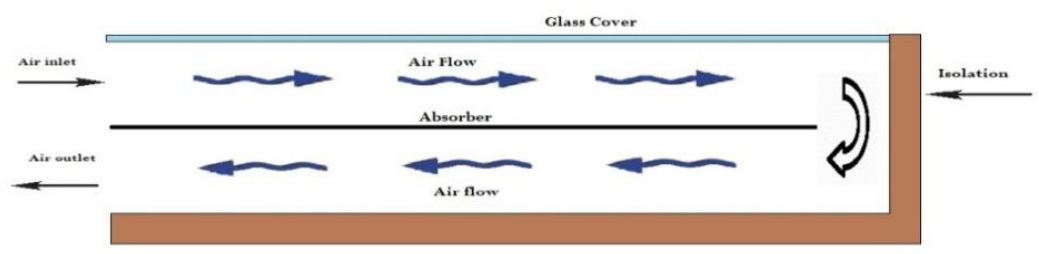

Figure 2: Side view for the collector 


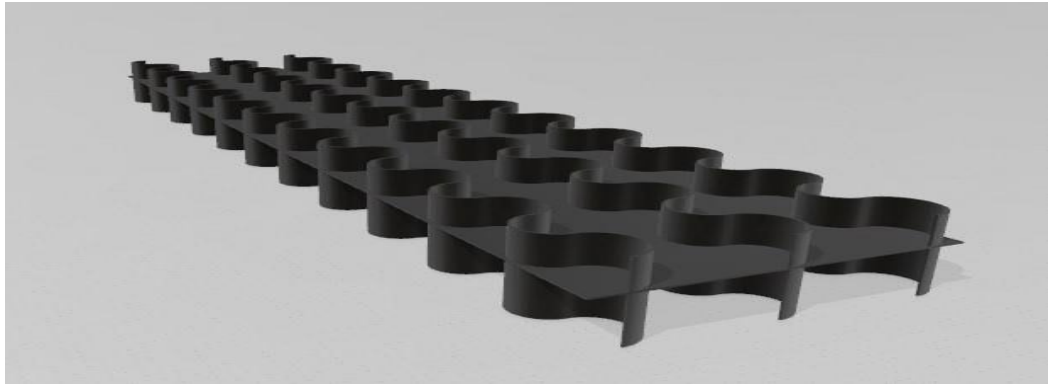

Figure 3: The general geometry for wave fins attached to both side of absorber (upper and lower)

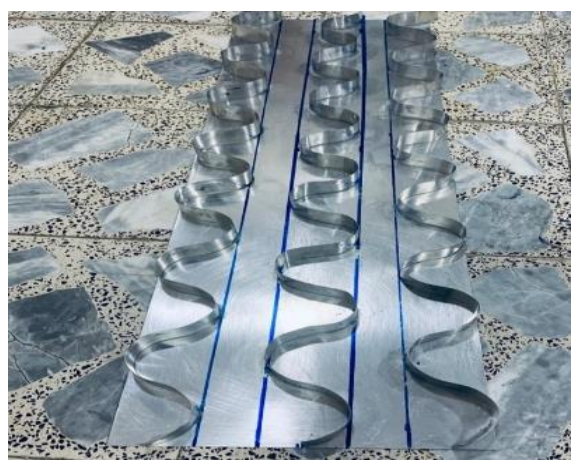

(A)

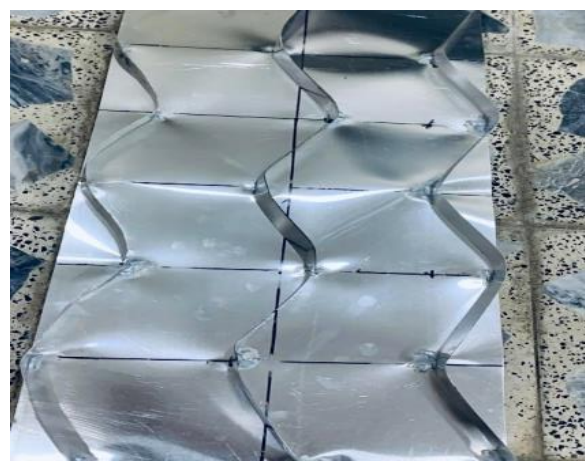

(B)

Figure 4: Types of absorbers (A) seven waves fin absorber (B) three waves fin absorber

\section{Theoretical calculation}

The thermal efficiency of the solar collector heater will be determined. To calculate the efficiency some parameters need to be calculated such as the different between input and output air temperature. Moreover, the efficiency depends on the air properties and the solar radiation flux intensity. The thermal efficiency output parameters of plane and wavy finned absorber solar air collector solar air heater

The total heat gain, $Q_{u}(\mathrm{~W})$ is calculated as

$$
\begin{gathered}
\mathrm{Q}_{\mathrm{u}}=\dot{\mathrm{m}} \mathrm{C}_{\mathrm{p}}\left(\mathrm{T}_{\text {fout }}-\mathrm{T}_{\text {fin }}\right) \\
\dot{\mathrm{m}}=\rho \mathrm{uA}
\end{gathered}
$$

Hydraulic diameter calculation:

$$
D_{h}=\frac{4 A}{P}
$$

Reynolds number calculation:

$$
R e=\frac{u D_{h}}{v}
$$

The overall thermal efficiency of the solar heater will determined

$$
\eta_{\mathrm{th}}=\frac{\mathrm{Q}_{\mathrm{u}}}{\mathrm{IA} \mathrm{C}}
$$

Where,

$\dot{\mathrm{m}}$ is the mass flow rate of air $(\mathrm{kg} / \mathrm{s})$

$\mathrm{Cp}$ is the specific heat of air $(\mathrm{kJ} / \mathrm{kg}-\mathrm{K})$

$\mathrm{T}_{\text {fin }}$ and $\mathrm{T}_{\text {fout }}$ are the inlet and outlet air temperatures, respectively $\left({ }^{\circ} \mathrm{C}\right)$

$\rho$ is the density of the air $\left(\mathrm{kg} / \mathrm{m}^{3}\right)$

$\mathrm{u}$ is the velocity of the air $(\mathrm{m} / \mathrm{s})$

A is the area of upper channel of flow $\left(\mathrm{m}^{2}\right)$

I is the intensity of solar radiation $\left(\mathrm{W} / \mathrm{m}^{2}\right)$

$\mathrm{A}_{\mathrm{C}}$ the area of solar collector $\left(\mathrm{m}^{2}\right)$

$v$ the kinematic viscosity of the air $\left(\mathrm{m}^{2} / \mathrm{s}\right)$ 


\section{Result and discussion}

This section discussing different graphs for results of the experimental results and calculated terms. Comparison between three different absorbers, plane, 3 waves fin and 7 waves fin absorbers have been done, for the solar air heater for various solar radiation intensity and different air mass flow rate. Fig.5, 6 and 7 shows the effect of mass flow rate for different solar radiation and its effect on the temperature difference (different between input and output air temperature). Where the increasing of mass flow rate decreased the temperature difference, because at low speed more heat can be diffused from absorber to the air flow. The maximum temperature difference is $25{ }^{\circ} \mathrm{C}$ at air mass flow rate $(0.0085 \mathrm{~kg} / \mathrm{s})$ in $7 \mathrm{waves}$ fin absorber solar air collector, because the fin attached with will disturb the boundary layer thus allow more heat transfer between the absorber and air flow. Figs. 8, 9 and 10 illustrate the effect of solar radiation intensity changing on the temperature difference. The increasing of the solar radiation intensity increase temperature difference, due to increasing the absorber plate temperature because of black body absorbing the solar radiation and cover it into heat. The maximum temperature difference at $800 \mathrm{~W} / \mathrm{m}^{2}$ in ( 7 waves fin absorber solar air collector), due to the fins attached extended the absorbing area thus large area for absorbing solar radiation and for heat transfer convection between the absorber and air flow. Figure 11. displays the comparison of thermal efficiencies for 3 types absorbers of solar air collectors (plane, 3 waves fin and 7 waves fin absorber) as it's between thermal efficiency and air speed for $600 \mathrm{~W} / \mathrm{m} 2$ the efficiency in 7 waves fin higher than 3 waves fin and plane absorber, because large area for heat transfer, air will take longer time flowing inside the absorber channels, wavy fins will break the boundary layer and making swirls in the flowing due to the geometry of fins which it's make the heat transfer more efficient. Figure12. Demonstrate the relationship between Reynolds number and mass flow rate, Reynolds number start 2250 at $0.009 \mathrm{~kg} / \mathrm{s}$ mass flow rate and the maximum 6000 at 0.021 , it's clearly shows the flow mostly in turbulence range, and that will enhance the heat transfer due to the heat transfer coefficient increases when the fluid velocity increases. As the velocity of the fluid is increased it will eventually reach a level which will cause the fluid to form turbulence eddies where the boundary layer breaks away from the wall and mixes with the bulk of the fluid further from the solar collector channel wall.

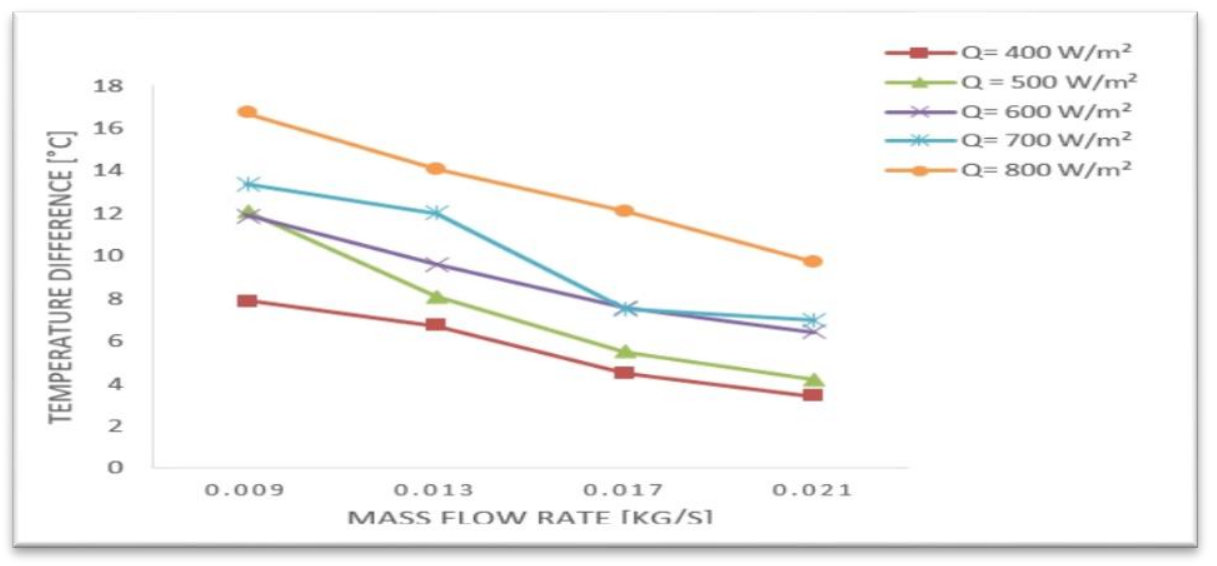

Figure 5: Variation of temperature difference with mass flow rate for different solar radiations (Plane absorber)

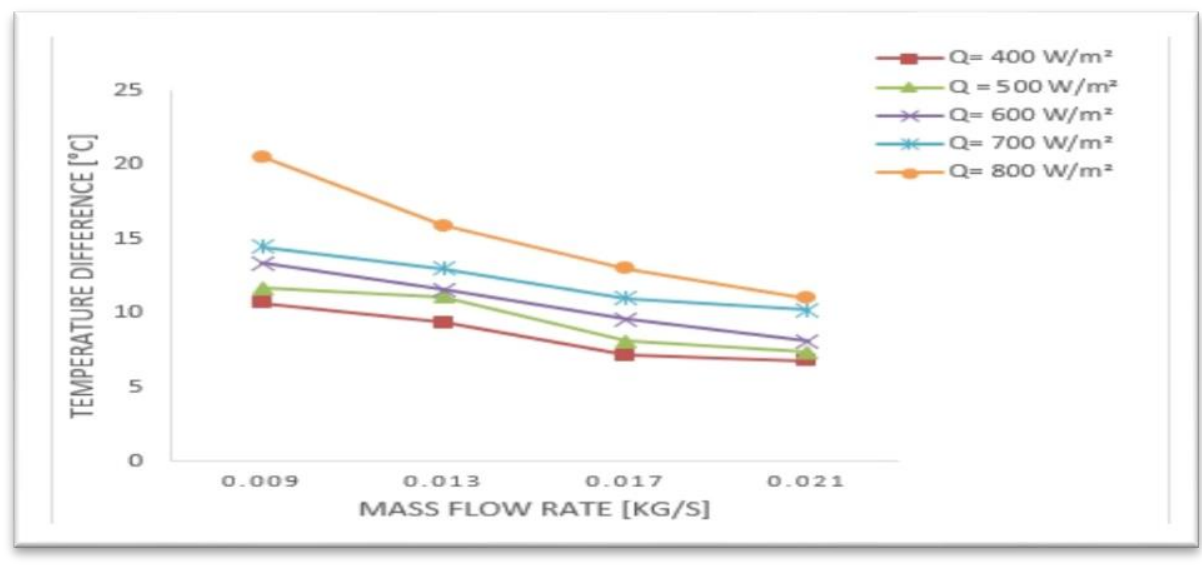

Figure 6: Variation of temperature difference with mass flow rate for different solar radiations(3 waves fin absorber) 


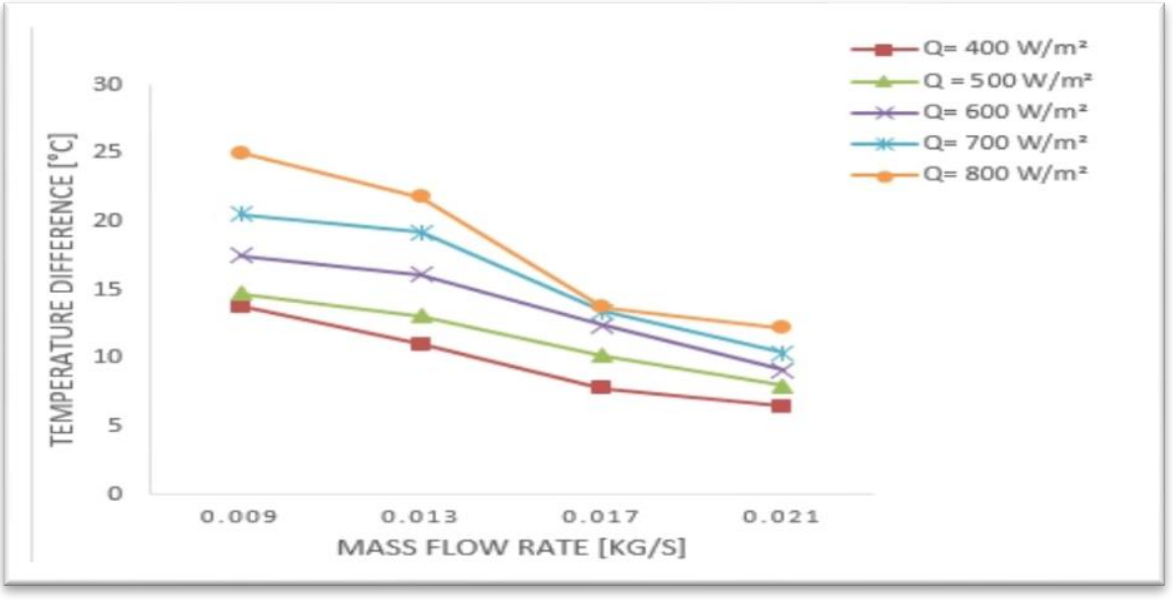

Figure 7: Variation of temperature difference with mass flow rate for different solar radiations (7 waves fin absorber)

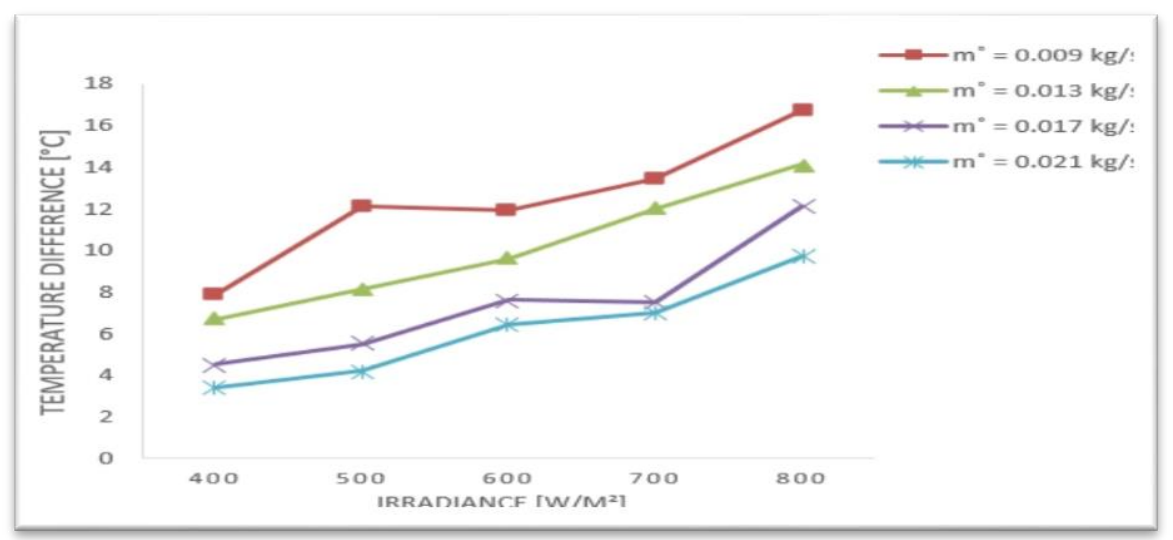

Figure 8: Variation of temperature difference with solar radiation for different mass flow rate(Plane Absorber)

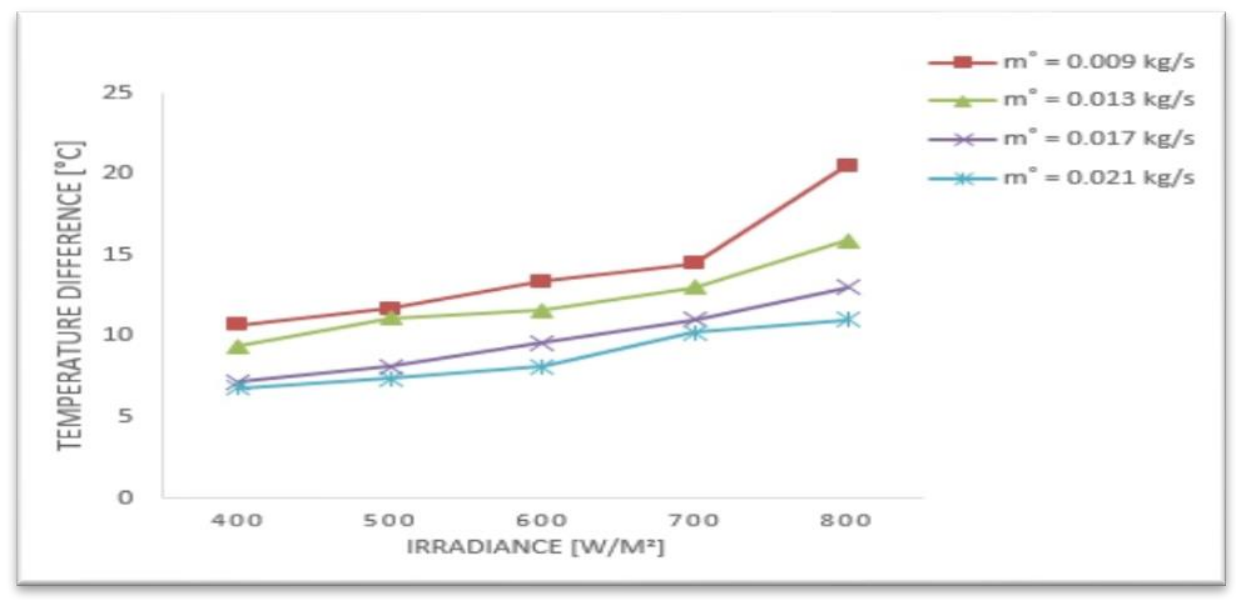

Figure 9: Variation of temperature difference with solar radiation for different mass flowrate(3waves fin absorber) 


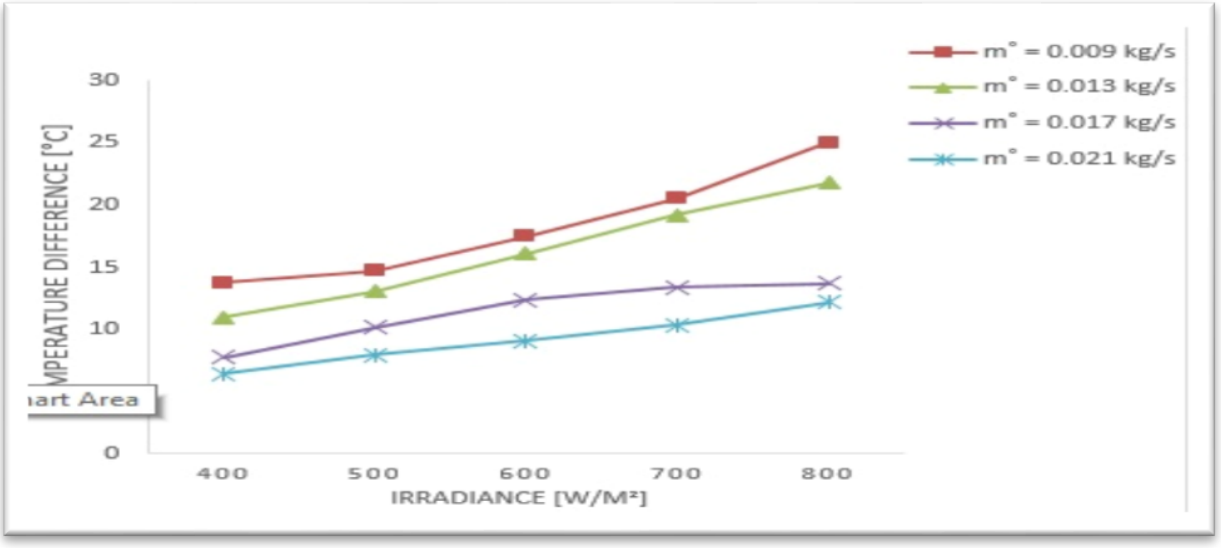

Figure 10: Variation of temperature difference with solar radiation for different mass flow rate (7 waves fin absorber)

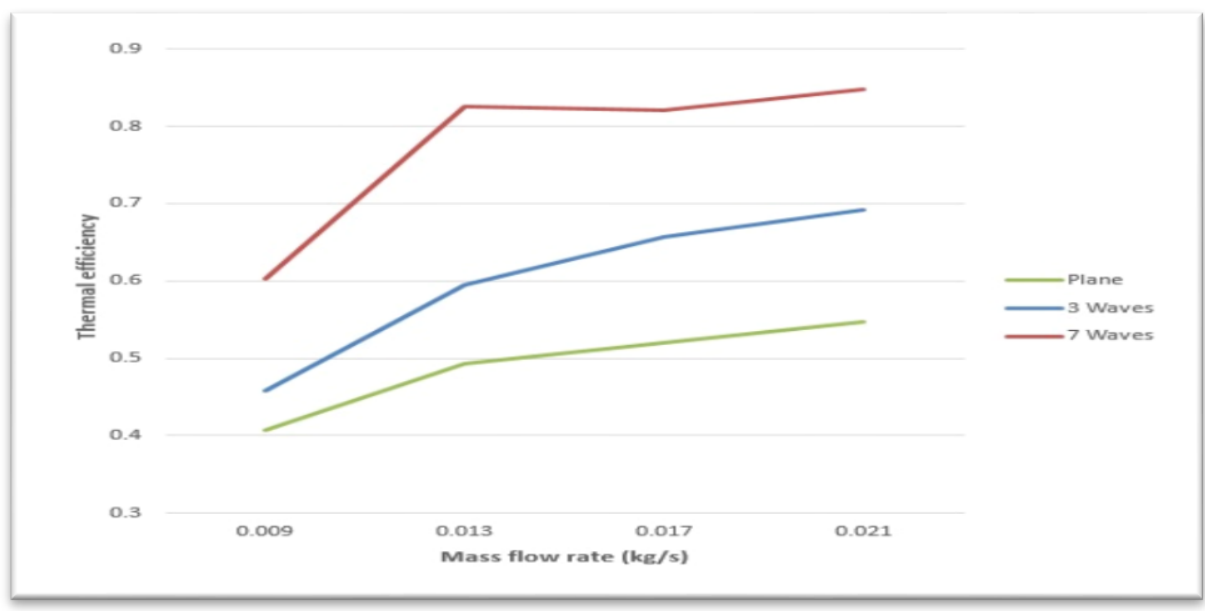

Figure 11: Comparison between thermal efficiencies for the cases (plane, 3 waves and 7 waves fin) atsolar radiation $600 \mathrm{~W} / \mathrm{m} 2$

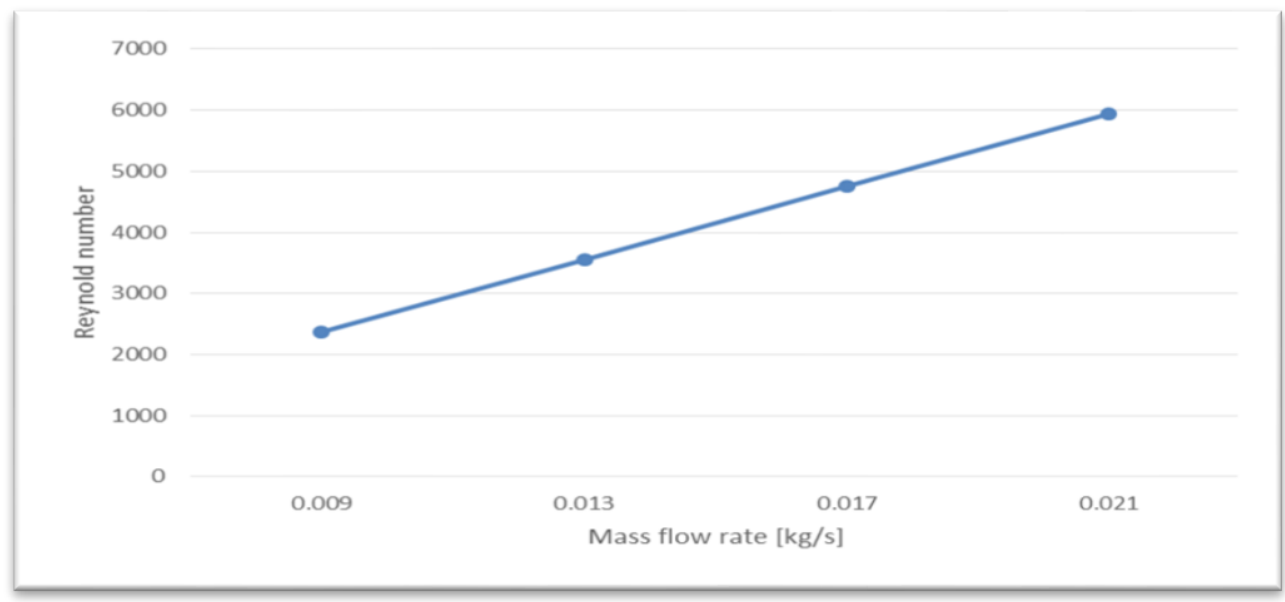

Figure 12: Reynolds number variation with different air mass flow rate

\section{Conclusions}

The extremal study on double pass solar air collector with improving the absorber by attaching wavy fins in different wave's number, based on the outcomes and discussion following conclusions can be drawn:

1) Increasing the solar radiation intensity will increase the temperature difference.

2) The results data shows that heat gain and thermal efficiency are strongly effected by air mass flow rate which its increase mean mass flow rate increases. 
3) Adding fins to the absorber plates will improve the thermal efficiency.

4) Thermal efficiency has an enhancement of $64.7 \%$ and $41.1 \%$ in 7 waves and three waves fin respectively in comparison to plane solar air heater.

\section{Author contribution}

All authors contributed equally to this work.

Funding

This research received no specific grant from any funding agency in the public, commercial, or not-for-profit sectors.

Data availability statement

The data that support the findings of this study are available on request from the corresponding author.

\section{Conflicts of interest}

The authors declare that there is no conflict of interest.

\section{References}

[1] A. Gaur, M. Bhayana, S.K. Agarwal, An experimental investigation of a novel design of a double pass solar air heater, Int. J. Chemtech Res., 5 (2013) 1036-1040.

[2] G. Maraba, An experimental study on enhancement of heat transfer in a solar air heater collector by using porous medium, M.Sc. thesis, School of Engineering and Sciences, Izmir Institute of Technology, Turkey, 2012.

[3] N. Rona, Solar air conditioning system, Book edition, Department of building technology -Chalmers University of technology, 2004.

[4] R. Karwa, Thermal Performance of Solar Air Heater Having Absorber Plate with V-Down Discrete Rib Roughness for Space-Heating Applications, Hindawi Publishing Corporation, Article ID $151578,2013$. https://doi.org/10.1155/2013/151578

[5] J. K. Tonui, Y. Tripanagnostopoulos, Improved PV/T solar collectors with heat extraction by force Or natural air circulation. Renew. Energy, 32 (2007) 623-637.

[6] W. Gao, W. Lin, E. Lu., Numerical study on natural convection inside the channel between the flat plate cover and sinewave absorber of a cross-corrugated solar air-heater, Energy Convers. Manag. , 41 (2000) $145-151$. https://doi.org/10.1016/S0196-8904(99)00098-9

[7] G. Sugantharaj, K.Vijay, K. Kulundaivel, Performances of packed bed double pass solar air heater with different inclinations and transverse wire mesh with different intervals, Thermal Sci., 20 (2014) 85-85. https://doi.org/10.2298/TSCI131015085S

[8] C. Choudhary, S. L. Andersen J. Rekstad, A solar air heater for low temperature applications, Solar Energy. 40 (1988) 335343. https://doi.org/10.1016/0038-092X(88)90006-0

[9] A. A. El-Sebaii, S. Aboul-Enein, Ramadan, M.R.I. Shalaby S.M, B.M. Moharram, Thermal performance investigation of double pass finned plate solar air heater, Appl. Energy. 88 (2011) 1727-1739. https://doi.org/10.1016/j.apenergy.2010.11.017

[10] T. Alam, M. Kim, Performance improvement of double-pass solar air heater - A state of art of review, Renew. Sustain. Energy Rev. 79 (2017) 779-793. https://doi.org/10.1016/j.rser.2017.05.087

[11] J.A. Duffie and W.A. Beckman, Solar Engineering of Thermal Processes, Wiley, 4th ed, New York, 1980.

[12] N. F. Jouybari \& T. S. Lundström, Performance improvement of a solar air heater by covering the absorber plate with a thin porous material, Energy, 190 (2020) 116437. https://doi.org/10.1016/j.energy.2019.116437

[13] H.P. Garg, G. Datta, A.K. Bhargava, Performance studies on a finned- air heater, Energy,14 (1989) 87-92.

[14] S.B. Thombre., S.P. Sukhatme, Turbulent flow heat transfer and friction factor characteristics of shrouded fin arrays with uninterrupted fins, Exp. Therm Fluid Sci. , 10 (1995) 388-396. https://doi.org/10.1016/0894-1777(94)00059-H

[15] A. Priyam, P. Chand, Thermal and thermohydraulic performance of wavy finned absorber solar air heater, Sol. Energy, 130 (2016) 250-259. https://doi.org/10.1016/j.solener.2016.02.030

[16] A. Priyam, P. Chand, Effect of collector aspect ratio on the thermal performance of wavy finned absorber solar air heater. Energy power eng., (2016) 562-566. https://doi.org/10.5281/zenodo.1124371

[17] A. Priyam, P. Chand, Thermal performance of wavy finned absorber solar air heater, Int. J. Heat Technol., 36 (2018) 13931403. https://doi.org/10.18280/ijht.360431 